\title{
Transitional care of GH deficiency: when to stop GH therapy
}

\author{
M O Savage, W M Drake, P V Carroll and J P Monson \\ Department of Endocrinology, Barts and the Royal London School of Medicine and Dentistry, London, UK
}

(Correspondence should be addressed to Martin Savage, Department of Paediatric Endocrinology, St Bartholomew's Hospital, London EC1A 7BE, UK; Email: m.o.savage@qmul.ac.uk)

\begin{abstract}
While the benefits of growth hormone $(\mathrm{GH})$ therapy in adult hypopituitary patients with GH deficiency (GHD) are established, the role of continued GH therapy after final height in adolescent $\mathrm{GH}$-deficient patients remains unclear. Preliminary data suggest that cessation of GH on completion of linear growth may be associated with impairment of somatic development and adverse changes in body composition. For the present time, the decision whether to continue GH treatment in adolescent patients with GHD is best made on an individual basis. For such patients, continuity of care is crucial. Children and adults with GHD are usually managed by physicians in separate departments, who may focus on different aspects of treatment and care. Close collaboration between paediatric and adult physicians is essential to ensure smooth transition and to minimize the drop-out rate from followup. Given the previous period of treatment during childhood, paediatric physicians should be best placed to discuss the potential benefits of continuing GH therapy and instigate retesting of GH secretion. Many children with isolated idiopathic GHD will produce normal GH responses if retested at adult height. Patients with multiple pituitary hormone deficits are more likely to have ongoing GHD, as are patients who have received CNS irradiation. Quality of life does not appear to be decreased in adolescents with GHD who stop treatment, so achievement of satisfactory bone mass is a major determinant of the decision whether to continue therapy.
\end{abstract}

European Journal of Endocrinology 151 S61-S65

\section{Introduction}

The benefits of treating severely growth hormone (GH)deficient children with recombinant human $\mathrm{GH}$, in order to facilitate linear growth, are firmly established. If therapy is commenced early and continued for long enough, affected children achieve adult heights that are within the normal range (1). Given that growth failure is the commonest presenting feature of $\mathrm{GH}$ deficiency (GHD) in children, the goal of therapy has, traditionally, been statural, with cessation of treatment when adult height is attained. The relatively recent recognition of a clinical syndrome associated with $\mathrm{GH}$ deficiency in adults, and the fact that many of its features are favourably influenced by treatment with GH $(2,3)$, raises the possibility that, for some patients, GH therapy may need to continue after reaching final height. This demands a critical re-evaluation of the process by which adolescent GH-deficient patients are best transferred from the care of a paediatric endocrinologist into an adult endocrine clinic and when GH therapy should be discontinued.

\section{Retesting of GH secretion at completion of growth}

A substantial proportion of children with isolated GHD (IGHD) will have recovered normal GH reserve by the time adult height is attained (4). This is particularly likely in those previously diagnosed with partial GHD (i.e. peak $\mathrm{GH}, 10-20 \mathrm{mU} / \mathrm{l}, 3.3-6.7 \mu \mathrm{g} / \mathrm{l}$ ) on dynamic testing or low 24-h integrated GH secretion. Patients with multiple pituitary hormone deficits (MPHD), with or without structural pituitary or peri-pituitary disease, are more likely to have ongoing GHD (5), and previous cranial irradiation is also a predictor of ongoing GHD (6). However, examples clearly exist both of patients with IGHD in childhood who subsequently satisfy the criteria for severe GHD when retested as adults, and of children with MPHD who have normal GH reserve on retesting (7). Hence, although it seems reasonable to advise patients with IGHD (particularly those with 'borderline' diagnostic results) that they are unlikely to require ongoing GH therapy into adult life, retesting of GH reserve is strongly advised in all patients on completion of linear growth, with the possible exception of genetic GH deficiency, as there is a possibility that GHD may persist into adulthood.

Current guidelines from a consensus meeting on the diagnosis of GHD in adults suggest that two biochemical tests of $\mathrm{GH}$ status are required in patients with IGHD, whereas a single GH-provocation test is sufficient in patients with MPHD (8). This has been advised because the peak GH concentrations obtained in patients with IGHD typically vary depending on the test used. In contrast, measurements of peak $\mathrm{GH}$ 
concentration in patients with MPHD are typically reliable irrespective of the test used. The insulin tolerance test (ITT) remains the 'gold standard' for testing $\mathrm{GH}$ reserve and has been shown to be safe and reliable when performed in experienced endocrine units, provided that there is strict adherence to the exclusion criteria $(9,10)$. An alternative test in patients for whom the ITT is contraindicated (or as the second test in patients with IGHD) is the combined arginine/GHreleasing hormone test (8). In adolescents, as in adults, a serum concentration of insulin-like growth factor I (IGF-I) below the lower end of the age-adjusted normal range is highly suggestive of GHD in patients with MPHD (7).

\section{Effects of discontinuation of GH at final height}

Although it is clear that many of the adverse pathophysiological features of the adult GHD syndrome are improved by GH replacement $(2,3)$, such observations alone do not provide sufficient basis for the continuation of $\mathrm{GH}$ therapy in $\mathrm{GH}$-deficient adolescents once growth is complete. Nor is it satisfactory to quote data from studies in which patients with childhood-onset GHD (CO-GHD) have subsequently been treated with $\mathrm{GH}$ in adult life, as such studies have usually been initiated several years after the discontinuation of GH therapy. As patients with CO-GHD have lower serum IGF-I levels, a lower lean body mass, reduced height, less reduction in quality of life (QoL) and less marked derangement of serum lipoprotein levels than patients with adult-onset GHD (AO-GHD), it has been argued that the two should be considered as separate entities (11). Given that the rationale for continuing $\mathrm{GH}$ treatment is partly to prevent adult GHD, it is appropriate to review whether withdrawal of GH therapy in this patient group is associated with adverse pathological changes.

\section{Body composition}

Observational discontinuation studies provide some evidence that withdrawal of GH therapy in adolescents who have completed their growth is associated with adverse changes in body composition (12, 13). Although both studies were small (eight and six patients respectively), analysis of these and other, similar, studies suggests that withdrawal of $\mathrm{GH}$ at the completion of final height is associated with a decrease in muscle strength and an increase in fat mass (14). However, such studies require cautious interpretation on account of the fact that a substantial proportion of patients treated with $\mathrm{GH}$ replacement in childhood show evidence of normal GH status by the time they achieve final height $(4,15)$. In addition, interpretation of data from discontinuation studies is made more difficult by the fact that serum IGF-I concentrations in patients who have persisting GHD are often markedly higher than those in patients with normal GH reserve (16). In other words, the observed changes in body composition may relate more closely to the reversal of GH excess than to the discontinuation of 'physiological' doses of GH.

Vahl et al. randomized 19 patients either to placebo or to continue with their regular paediatric weightbased GH dose, 2.0-5.0 IU/day (0.7-1.7 mg/day) for 12 months after final height, followed by a further 12 months of GH therapy in all patients (17). No change in lean body mass (LBM) was evident over 1 year in either group, but there was a significant increase in LBM when placebo-treated patients subsequently restarted GH. Total body fat (TBF) increased significantly in the placebo-treated patients, but this was largely reversed during the open-label $\mathrm{GH}$ phase of the study. Interestingly, despite this change in TBF, there were no significant differences in insulin sensitivity between the two groups (18).

In a recent, preliminary, report of a UK multi-centre study of similar design, 24 adolescent patients either stopped GH therapy or continued with a weight-based dosing regimen of $0.35 \mathrm{IU} / \mathrm{kg} /$ week $(0.12 \mathrm{mg} / \mathrm{kg} /$ week $)$ for 12 months (19). In those who discontinued GH therapy, LBM remained static. In contrast, there was an approximate $4 \%$ increase in LBM in patients who continued on GH (Fig. 1). No statistically significant change in total, truncal or percentage fat was observed in either group, although a trend towards an increase in all three measures was noted in patients who discontinued GH. Despite these increases in fat mass, there was a significant improvement in insulin sensitivity following cessation of $\mathrm{GH}$, as determined by the short insulin tolerance test (sITT). A similar non-significant trend in insulin sensitivity was observed when assessed by a homeostatic model. No changes in insulin sensitivity were noted using either method in patients remaining on $\mathrm{GH}$ therapy.

The results of these two studies are not completely consistent with the established adult model of hypopituitarism, in which increased central adiposity is associated with relative insulin resistance. The insulin

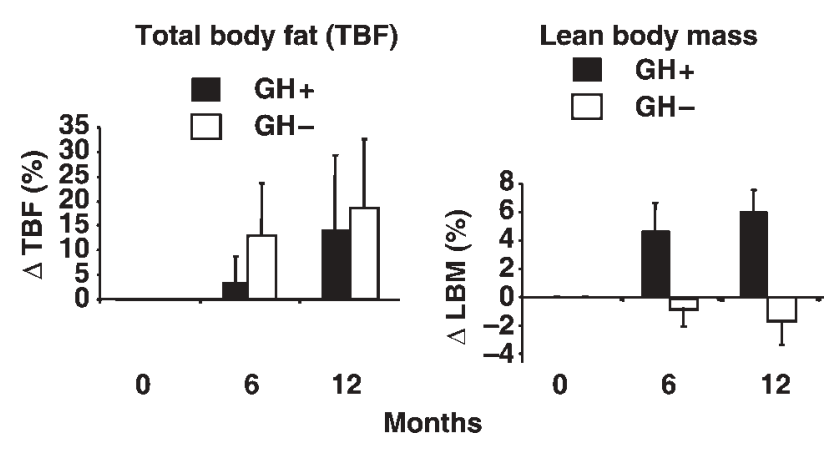

Figure 1 Body composition changes in GH-deficient adolescents who continue or discontinue GH therapy. Results are means \pm S.E.M. 
antagonistic' effects of GH are postulated to be due, at least in part, to its lipolytic action, with consequent mobilisation of free fatty acids. This leads to Randle cycle substrate competition between glucose and lipid fuels in the periphery, increased insulin secretion and a state of partially compensated hyperinsulinaemia (20). A relative insulin-resistant state caused by GH action may, potentially, be advantageous to the adolescent patient because of the increased anabolism associated with higher circulating insulin concentrations.

\section{Bone mineral density}

Peak bone mass (PBM), defined as the highest level of bone mass achieved as a result of normal growth, together with subsequent age-related loss, is an important determinant of an individual's risk of osteoporosisrelated fracture in later life $(21,22)$. During puberty, areal bone mineral content (BMC) and density (BMD) increase four- to sixfold over 3 years $(11-14$ in girls and 13-16 in boys) (22), such that approximately $37 \%$ of skeletal mass is acquired between pubertal stages 2 and 5 (22). Increased gonadal steroid secretion around the time of puberty is the most important hormonal regulator of bone accretion, but the anabolic effects of GH in vitro, together with the beneficial effects of $\mathrm{GH}$ replacement on bone remodelling and BMD in adult hypopituitarism, have highlighted the possible role of $\mathrm{GH}$ in the attainment of PBM.

Patients with CO-GHD are relatively osteopaenic compared with age-matched healthy controls (23, 24). This is true both for patients with IGHD and those with MPHD (24), suggesting that it is the GHD per se, rather than inadequate/supraphysiological replacement of deficient anterior pituitary hormones that is the cause of the low bone mass. However, cross-sectional studies using dual-energy X-ray absorptiometry should be interpreted with caution, as an important determinant of areal BMD is bone size (25). Hence, it is possible that the observed deficits in bone mass were due, at least in part, to a period of untreated GHD prior to the commencement of childhood therapy and/or suboptimal replacement of GH. The latter possibility is supported by the observation that patients treated with recombinant human $\mathrm{GH}$ have a greater bone mass than patients with similar aetiologies of GHD treated with cadaveric GH (26).

A recent UK multicentre study examined the skeletal consequences of discontinuation/continuation of $\mathrm{GH}$ therapy in 24 adolescent patients with severe GHD, according to adult criteria (27). Continuation of GH at a fixed weight-based dose of $0.35 \mathrm{IU} / \mathrm{kg} /$ week $(0.12 \mathrm{mg} / \mathrm{kg} /$ week) was associated with an increment in whole body BMC approximately 3\% greater than that observed in patients who discontinued $\mathrm{GH}(6 \%$ rise in the GH-treated patients vs $3 \%$ in those who discontinued GH) (Fig. 2). This extra increase in BMC would represent 2 years of bone loss later in life in a

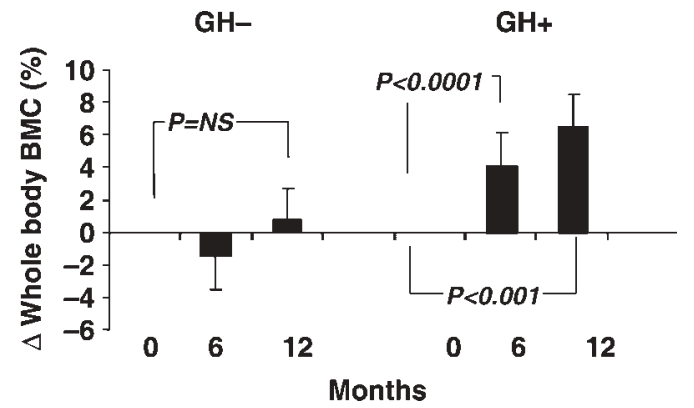

Figure 2 Change in whole body bone mineral content (BMC) vs time in GHD adolescents who discontinue or continue $\mathrm{GH}$. Results are means \pm S.E.M. NS, not significant.

typical postmenopausal woman (28). Interestingly, the $6 \%$ increase in BMC in those who continued $\mathrm{GH}$ approximates to that observed in previous longitudinal studies in healthy adolescents $(21,22)$ and parallels the change in LBM reported in the same cohort of patients (19).

The mechanism underlying the apparent disadvantage of those patients who discontinued GH was not clearly identified, although the fall in bone-specific alkaline phosphatase (BSAP) between 0 and 6 months in those who discontinued GH is suggestive of a reduction in osteoblastic activity (Fig. 3). A larger study examining the relationship between baseline markers of bone turnover and subsequent bone mineral accretion is required to clarify this point.

In a separate 2-year study, Shalet and colleagues randomised 149 young adults to one of three groups: no treatment, $\mathrm{GH} 0.025 \mathrm{mg} / \mathrm{kg} /$ day (paediatric dose) or GH $0.0125 \mathrm{mg} / \mathrm{kg} /$ day (adult dose) (29). All had been treated with GH to final height for a diagnosis of GHD made in childhood, although, unlike the study reported above, the time since discontinuing $\mathrm{GH}$ therapy varied between 6 weeks and 5 years. Mean BMC increased in the control group by $5.6 \%$ over 2 years. In the GH-treated patients, BMC increased by $9.5 \%$ (adult dose) and $8.1 \%$ (paediatric dose), further supporting the notion that withdrawal of $\mathrm{GH}$ replacement in young adult GHD patients limits the progression towards peak bone mass. Certain patients may be

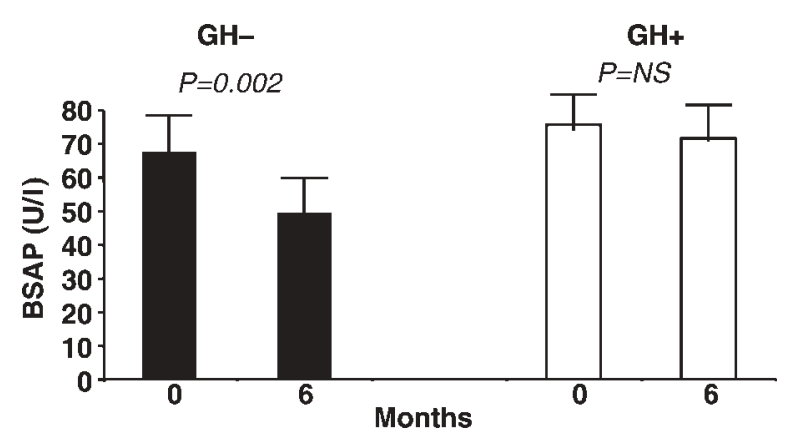

Figure 3 Bone specific alkaline phosphatase (BSAP) values vs time in $\mathrm{GH}$-deficient adolescents who discontinue or continue $\mathrm{GH}$ therapy. Results are means \pm S.E.M. NS, not significant. 
closer than others to peak bone mass at final height and may therefore have more to gain by continuation of GH.

\section{Markers of cardiovascular risk}

In adolescent $\mathrm{GH}$-deficient patients there is no evidence that discontinuation of $\mathrm{GH}$ results in the characteristic derangement of the lipid profile seen in patients with AO-GHD. However, it is important to note that the duration of both studies was only 12 months and such data should be interpreted in the light of the obvious complexity of the role of GH in determining insulin sensitivity in this age group. Larger studies of longer duration will be required to determine whether this aspect of the adult GHD syndrome evolves in adolescent GH-deficient patients. No data from continuation/discontinuation studies are currently available regarding fibrinogen, plasminogen-activating inhibitor or intima-media thickness in this patient group.

\section{Strategy for GH therapy at completion of growth}

In the absence of compelling data to justify widespread continuation of GH into adult life, and the lack of evidence that a delay in re-introducing therapy has deleterious consequences, several possible strategies exist. One approach would involve the seamless continuation of GH into adult life, with only a brief cessation of therapy to allow re-assessment of GH status. A second option, given that the greatest short-term benefit of $\mathrm{GH}$ replacement in adult life is improved well-being, would be to offer GH replacement only to those patients who demonstrate the greatest disadvantage in terms of QoL on withdrawal of $\mathrm{GH}$ at final height. A proportion of adult GHD patients, particularly those with CO-GHD, report entirely normal QoL when off treatment (11). Hence, a period of cessation of GH would help to determine whether GH therapy is likely to be symptomatically beneficial. The practice of universal continuation of GH from childhood to adulthood would not identify such patients. In addition, compliance with therapy is likely to be improved in patients who experience a period of symptomatic GHD prior to subsequent recommencement of GH. A third strategy would be to continue with GH for some years after linear growth is complete in order to facilitate the development of PBM, followed by discontinuation of therapy with subsequent re-evaluation.

\section{Summary}

There is preliminary evidence that withdrawal of $\mathrm{GH}$ therapy on completion of linear growth in GH-deficient adolescents may be associated with incomplete skeletal development and adverse changes in body composition. To date, there is little evidence that such patients are significantly disadvantaged in terms of QoL, insulin sensitivity or surrogate markers of cardiovascular risk, and it is clear that the role of $\mathrm{GH}$ in determining insulin sensitivity in this age group and the evolution of this aspect of the adult GHD phenotype requires further clarification.

\section{References}

1 Blethen SL, Baptista J, Kuntze J, Foley T, LaFranchi S \& Johanson A. Adult height in growth hormone (GH)-deficient children treated with biosynthetic GH. The Genentech Growth Study Group. Journal of Clinical Endocrinology and Metabolism $1997 \mathbf{8 2}$ 418-420.

2 Jørgensen JO, Pedersen SA, Thuesen L, Jorgensen J, IngemannHansen T, Skakkebaek NE \& Christiansen JS. Beneficial effects of growth hormone treatment in GH-deficient adults. Lancet 1989 1 1221-1225.

3 Salomon F, Cuneo RC, Hesp R \& Sönksen PH. The effects of treatment with recombinant human growth hormone on body composition and metabolism in adults with growth hormone deficiency. New England Journal of Medicine 1989321 1797-1803.

4 Tauber M, Moulin P, Pienkowski C, Jouret B \& Rochiccioli P. Growth hormone $(\mathrm{GH})$ retesting and auxological data in 131 GH-deficient patients after completion of treatment. Journal of Clinical Endocrinology and Metabolism 199782 352-356.

5 Toogood AA \& Shalet SM. Diagnosis of severe growth hormone (GH) deficiency in young adults who received GH replacement therapy during childhood. Acta Paediatrica Supplement 1997 $423117-120$.

6 Nicolson A, Toogood AA, Rahim A \& Shalet SM. The prevalence of severe growth hormone deficiency in adults who received growth hormone replacement in childhood. Clinical Endocrinology $199644311-316$.

7 Shalet SM, Toogood A, Rahim A \& Brennan BM. The diagnosis of growth hormone deficiency in children and adults. Endocrine Reviews $199819203-223$.

8 Consensus guidelines for the diagnosis and treatment of adults with growth hormone deficiency: summary statement of the Growth Hormone Research Society Workshop on Adult Growth Hormone Deficiency. Journal of Clinical Endocrinology and Metabolism $1998 \mathbf{8 3} 379-381$.

9 Lange M, Svendsen OL, Skakkebaek NE, Muller J, Juul A, Schmiegelow M \& Feldt-Rasmussen U. An audit of the insulin-tolerance test in 255 patients with pituitary disease. European Journal of Endocrinology $2002 \mathbf{1 4 7} 41-47$.

10 Jones SL, Trainer PJ, Perry L, Wass JA, Bessser GM \& Grossman A. An audit of the insulin tolerance test in adult subjects in an acute investigation unit over one year. Clinical Endocrinology $1994 \mathbf{4 1}$ $123-128$.

11 Attanasio AF, Lamberts SW, Matranga AM, Birkett MA, Bates PC, Valk NK, Hilsted J, Bengtsson BA \& Strasburger CJ. Adult growth hormone (GH)-deficient patients demonstrate heterogeneity between childhood onset and adult onset before and during human GH treatment. Adult Growth Hormone Deficiency Study Group. Journal of Clinical Endocrinology and Metabolism $1997 \mathbf{8 2}$ $82-88$.

12 Rutherford OM, Jones DA, Round JM, Buchanan CR \& Preece MA. Changes in skeletal muscle and body composition after discontinuation of growth hormone treatment in growth hormone deficient young adults. Clinical Endocrinology $1991 \quad 34$ $469-475$.

13 Colle M \& Auzerie J. Discontinuation of growth hormone therapy in growth-hormone-deficient patients: assessment of body fat mass using bioelectrical impedance. Hormone Research 199339 $192-196$. 
14 de Boer H \& van der Veen EA. Why retest young adults with childhood-onset growth hormone deficiency? Journal of Clinical Endocrinology and Metabolism 199782 2032-2036.

15 Wacharasindhu S, Cotterill AM, Camacho-Hubner C. Besser GM \& Savage MO. Normal growth hormone secretion in growth hormone insufficient children retested after completion of linear growth. Clinical Endocrinology 199645 553-556.

16 Johannsson G, Albertsson-Wikland K \& Bengtsson BA. Discontinuation of growth hormone $(\mathrm{GH})$ treatment: metabolic effects in GH-deficient and GH-sufficient adolescent patients compared with control subjects. Swedish Study Group for Growth Hormone Treatment in Children. Journal of Clinical Endocrinology and Metabolism 199984 4516-4524.

17 Vahl N, Juul A, Jorgensen JO, Orskov H, Skakkebaek NE \& Christiansen JS. Continuation of growth hormone $(\mathrm{GH})$ replacement in GH-deficient patients during transition from childhood to adulthood: a two-year placebo-controlled study. Journal of Clinical Endocrinology and Metabolism 200085 1874-1881.

18 Norrelund H, Vahl N, Juul A, Moller N, Alberti KG, Skakkebaek NE, Christiansen JS \& Jørgensen JO. Continuation of growth hormone $(\mathrm{GH})$ therapy in $\mathrm{GH}$-deficient patients during transition from childhood to adulthood: impact on insulin sensitivity and substrate metabolism. Journal of Clinical Endocrinology and Metabolism 200085 1912-1917.

19 Carroll PV, Drake WM, Metcalfe KA, Maher KT, Savage MO, Dunger DB, Shaw NJ, Cheetham TD, Camacho-Hubner C \& Monson JP. Growth hormone (GH) treatment is an important regulator of insulin sensitivity in the adolescent with severe GHdeficiency. 84th Annual Endocrine Meeting of the Endocrine Society, San Francisco 2002 P3-578.

20 Randle PJ, Garland PB, Hales CN \& Newsholme EA. The glucose fatty-acid cycle. Its role in insulin sensitivity and the metabolic disturbances of diabetes mellitus. Lancet $1963 \mathbf{1}$ 785-789.

21 Bonjour JP, Theintz G, Buchs B, Slosman D \& Rizzoli R. Critical years and stages of puberty for spinal and femoral bone mass accumulation during adolescence. Journal of Clinical Endocrinology and Metabolism 199173 555-563.

22 Matkovic V, Jelic T, Wardlaw GM, Ilich JZ, Goel PK, Wright JK, Andon MB, Smith KT \& Heaney RP. Timing of peak bone mass in Caucasian females and its implication for the prevention of osteoporosis. Inference from a cross-sectional model. Journal of Clinical Investigation 199493 799-808.

23 Kaufman JM, Taelman P, Vermeulen A \& Vandeweghe M. Bone mineral status in growth hormone-deficient males with isolated and multiple pituitary deficiencies of childhood onset. Journal of Clinical Endocrinology and Metabolism 1992 74 118-123.

24 de Boer H, Blok GJ, van Lingen A, Teule GJ, Lips P \& van der Veen EA. Consequences of childhood-onset growth hormone deficiency for adult bone mass. Journal of Bone and Mineral Research 19949 1319-1326.

25 Genant HK, Engelke K, Fuerst T, Gluer CC, Grampp S, Harris ST, Jergas M, Lang T, Lu Y, Majumdar S, Mathur A \& Takada M. Non-invasive assessment of bone mineral and structure: state of the art. Journal of Bone and Mineral Research 199611 $707-730$.

26 Saggese G, Baroncelli GI, Bertelloni S \& Barsanti S. The effect of long-term growth hormone (GH) treatment on bone mineral density in children with GH deficiency. Role of GH in the attainment of peak bone mass. Journal of Clinical Endocrinology and Metabolism $1996813077-3083$.

27 Drake WM, Carroll PV, Maher KT, Metcalfe KA, Camacho-Hubner C, Shaw NJ, Dunger DB, Cheetham TD, Savage MO \& Monson JP. The effect of cessation of growth hormone $(\mathrm{GH})$ therapy on bone mineral accretion in GH-deficient adolescents at the completion of linear growth. Journal of Clinical Endocrinology and Metabolism $2003 \mathbf{8 8} 1658-1663$.

28 Effects of hormone therapy on bone mineral density: results from the postmenopausal estrogen/progestin interventions (PEPI) trial, The Writing Group for the PEPI. Journal of the American Medical Association $19962761389-1396$.

29 Attanasio AF, Howell S, Bates PC, Chipman J, Blum WF \& Shalet SM. Body composition, IGF-I, IGFBP-3 concentrations as outcome measures in severely GH deficient (GHD) patients after childhood GH treatment: a comparison with adult onset GHD patients. Journal of Clinical Endocrinology and Metabolism 2002 $873368-3370$

Received 5 April 2004

Accepted 3 May 2004 